\title{
The Social Service Function is the Main One among Four Functions for Nowadays Universities
}

\author{
Liu Keke \\ University of Jinan, Jinan, Shandong, China, 250022
}

\begin{abstract}
There have been four functions for nowadays universities: talent cultivation, scientific research, social service and cultural passing and creation. The social service function is the main one among them because the position of running school, which is to foster application type talents and the role of district economy in social development. The article states the functions, the connotation and the aims of the district universities.
\end{abstract}

KEYWORD: District University; social service; connotation and aims

As an important combination of science and technology to the first productivity and the first resource for the talents, the higher education is playing the key role in the nation's development. Continuous quality improvements, a lifeline in the higher education, should be penetrated among the works as fostering the talents, scientific research, social services and cultural inheritance and innovation. We must adapt the requirements to make the economic society develop excellently and quickly, to promote the comprehensive developments of the talents and to push the society forward. We should insist on connotative development, have international advanced ideas and experiences, improve the qualities of the higher education in full-scale and provide the talents and intelligence for the socialist modernization construction. The speech of Hu Jintao, the General Secretary, is the guild for the district universities sure of the function to serve the society.

\section{THE FUNCTIONS OF SERVING SOCIETY IN THE DISTRICT UNIVERSITIES}

Entering the 21st century, especially after America 911 Event, the higher education has experienced two common changes worldwide. On one hand, international level of the university has been increasing improved. There appears a standard estimated university according to international standards. On the other hand, universities stated to make use of their special advantages to promote exchanges and fusions between different cultures to eliminate the conflicts between different cultures and push the world to be harmonious. In 2011, Hu Jintao, the General Secretary classified inheritance and innovation as the forth one in the functions of the universities at Anniversary of 100 years of Qinhua University.

In the opinion of the writer of the paper, seeing from the angle of value and functions, the local universities serve as four functions: the cultivation of talents, the science research, the contributions to the society and the passage and the renovation of culture. The four functions are in separable just like the four wheels of a car, with the contribution to the society being the driving wheel, because universities have turned into "the core institutions of modern society",[1] the engine of one country's economy. The revitalization of the country, the government and the people demands that universities serve the society well. Universities are in fact not longer the ivory towers; instead, they are closely connected with all the aspects of the society, exchanging materials, energy, information, system and space. 
2 THE CULTIVATION OF CONNOTATIONS OF LOCAL UNIVERSITIES' ROLE FOR SERVING THE SERVING THE SOCIETY

Local universities should focus on the general objective of the establishment of universities. They should get familiar with the situation of economy, society and culture, and understand well the essence of education and teaching, science research, subject establishment, and culture establishment.

Local universities should create a university's brain trust and think tank, attach great importance to their association with the outside and reinforce their communication with the society, pay attention to the issues of the society, because their important responsibilities is to help to take the society and economy take off and lead the development of culture. Take Shandong Province as an example, the 12th Five-year Scheme Outline for the Development of Shandong Province's Economy and Society points out, the local government should carry out the project for reform and upgrade of traditional industries, attach greater importance to the development of such industries as engineering machinery and electrical equipment, make the advanced equipment manufacturing industry stronger; regulate and optimize raw material industries, improve the development level of such primary industries as building materials and mechanical engineering, attach greater importance to the five industries such as new material, new information and new medicine; strive to develop cultural industry, and push forward the development of the industry to make it into a pillar industry. The 12th Five-year Scheme Outline for the Development of Jinan City's Economy and Society points out, the local government should accelerate the speed by which such traditional industries as petrifaction and building material will be updated and advanced with high-tech and advanced practical technologies; strive to develop information service industry, make a service-prior economy; integrate such spring cultural resources as local folk customs, cultivate and strengthen many a spring cultural images and create such images characteristic of Spring City; accelerate the strategy of making the city more prosperous with the help of culture, strive to develop cultural undertakings and cultural industries. The abovementioned strategies provide the local universities in Shandong Province a better chance to thrive, and the universities in turn should make full use of the chance to make strategic changes in such aspects as talents cultivation, science research and society service, improve their service abilities and levels to serve the society in order to win capacious space for the future.

Third, three concepts stand out when local universities develop the institutions of social service. The first is to insist on the concept of open mind in the development on the institutional level of social service functional departments, for functional departments are universities and they ought to strengthen the communication with the outside parties on a variety of aspects, actively broaden the development space in order to realize the development of interaction between universities and society. In the second place, stick to the concept of nature in the development on the proceeding level of social service functional departments, focusing on the affection needs of the targets served, making sure to take advantage of people's virtues, avoid their weaknesses, and help them out of trouble. Thirdly, insist on the concept of reason in the development on the technological level of social service functional in the development, forming the high efficient structure of organizations, carrying on streamlined management, reducing hierarchies, connecting heart to heart among the large number of teachers and students, society, building the broad bridge between universities and society.

Concerning social service, local universities should utilize four kinds of resources, that is, government, news media, teachers and students in the universities and alumni.

Firstly, take good advantage of government resources. Local universities should establish strategic cooperative relations of mutual benefit and trust with local cities and concerned organizations and carry out extensive cooperation with government, entrepreneurs and social entities.

Secondly, take good advantage of news media resources. Make perfect the news planning, increase the strength of news publication, improve the popularity, reputation and placement of social service, and broaden the influence, competition and credibility of universities on the society.

Thirdly, take good advantage of resources of teachers and students in the universities. Set up contact spots and persons in all departments and schools, master the dynamic trend of talents cultivation, scientific research, discipline and cultural construction, launch them out to serve the local councils on time. Strengthen the leading of organizations and organic combination of carrying on social service and strengthening the construction of teachers and create good conditions for teachers with great specialty to engage in social service, inspiring the initiative of teachers to carry on social service[2].

Fourthly, take good advantage of alumni resources. Set up the contact spots of serving society in different places by using the organizations i.e. the alumni and educational funds and improve the landing rate of service. 
3 FOCUS ON SOCIAL SERVICE OF LOCAL UNIVERSITY----APPLICATION-ORIENTED TALENTS

According to UNESCO International Education Standard Classification revised in 1997. Although Subject-oriented professional education and application-oriented professional education belong to $5 \mathrm{~A}$ normal high education, there exist differences in training direction and function. Subject-oriented professional education belong to 5A1 which classified by subjects while application-oriented professional education belong to $5 \mathrm{~A} 2$ which stressed on classification in different industries. Accordingly application-oriented professional education is the second type of professional applied education (5A2) between 5A1 and vocational education (5B). This type of education is led by vocations. The main line is professional and practical. It is based on professional education and the characteristic is to combine subjects and vocations, training advanced talents to face the real society.[3]

From the experience of modernized process of western developed countries, demand for talent in economic and social development shows "olive" trend, which means academic talents and normal labors are minorities while those people with certain skills occupy the majorities in society. With development of our industries and high-tech. strategic adjustment of economic structure should be fastened. Traditional industries are replaced by hightech ones and transformation from labor-intensive to high-tech knowledge happens a lot. That trend requires not only skillful workers but also plenty of advanced engineers and management talents, who can do researches and experiments, can improve production level and make research work profound in the first line of manufacturing and managing.[4]

Provisions of the Law on Higher Education have also been made clear that colleges are independent legal person sponsoring entities. Thus every college should be equal only with difference in teaching level, characteristics and reputation. It's quite wrong to artificially divide colleges into various grades and ranks. To a college the most important thing is his brand, its own characteristics. So every type of colleges should make their own reputation in a down-to-earth manner on the appropriate level of running.

\section{REFERECNCES}

[1] John S Brubacher, On the Philosophy of Higher Education Translated by Wang chengxu Zhejiang Education Press, 1999.13.

[2] $\mathrm{Xu}$ xianming Culture Inheriting and Creation: the Establishment of Fourth Functions Chinese Higher Education Press, 2011.

[3] Pan Maoyuan, Theory and Practice on Applied Talent Cultivation, Xiamen University Press, 2011.

[4] Ganhong, Xudaqi, Updating Quality Conception on Cultivation of Applied Talent, Chinese Higher Education, 2011. 